\title{
ВЫЯВЛЕНИЕ ИЗМЕНЧИВОСТИ У РАСТЕНИЙ СМОРОДИНЫ ЧЕРНОЙ (RIBES NIGRUM L.), ПОЛУЧЕННЫХ IN VITRО ДЛЯ СЕЛЕКЦИИ В УСЛОВИЯХ БАШКИРИИ
}

\author{
L.A. Golovina, R.A. Nigmatzyanov, \\ V.N. Sorokopudov
}

\section{DETECTION OF VARIABILITY IN BLACK CURRANT PLANTS (RIBES NIGRUM L.) OBTAINED IN VITRO FOR SELECTION IN BASHKIRIA CONDITIONS}

Головина Людмила Андреевна - науч. сотр. Кушнаренковского селекционного центра по плодово-ягодным культурам и винограду Башкирского НИИ сельского хозяйства - обособленного подразделения УФИЦ РАН, Республика Башкортостан, Кушнаренковский р-н, с. Кушнаренково. E-mail: ludmilab_2010@mail.ru

Нигматзянов Радмил Асхатович - науч. сотр. Кушнаренковского селекционного центра по плодово-ягодным культурам и винограду Башкирского НИИ сельского хозяйства - обособленного подразделения УФИЦ РАН, Республика Башкортостан, Кушнаренковский р-н, с. Кушнаренково; науч. сотр. Института стратегических исследований Республики Башкортостан, г. Уфра.

E-mail: 79374839931@yandex.ru

Сорокопудов Владимир Николаевич - д-р с.-х. наук, проф. каф. декоративного садоводства и газоноведения Российского государственного аграрного университета - МСХА им. К.А. Тимирязева, г. Москва. E-mail: sorokopud2301@mail.ru

Смородина черная (Ribes nigrum L.) относится к числу наиболее ценных ягодных кустарников в Республике Башкортостан. Сортовой состав данной культуры представлен в основном высокоадаптивными сортами башкирской селекции. Сорта Караидель и Чишма являются высокоурожайными, высокозимостойкими, имеют полевую устойчивость к основньм болезням и вредителям, обладают хорошей побегообразовательной и побеговосстановительной способностью. На сегодняшний день сорта Караидель и Чишма задействованы в селекции смородины черной в качестве родительских форм для создания новых сортов. Цель работы - выявить изменчивость хозяйственно-биологических признаков сортов смо-
Golovina Ludmila Andreevna - Staff Scientist, Kushnarenkovo Selection Center for Fruit and Berry Cultures and Grapes, Bashkir Research and Development Institute of Agriculture - Separate Branch, UFRC RAS, the Republic of Bashkortostan, Kushnarenkovo District, V. Kushnarenkovo. E-mail: ludmilab_2010@mail.ru Nigmatzyanov Radmil Askhatovich - Staff Scientist, Kushnarenkovo Selection Center for Fruit and Berry Cultures and Grapes, Bashkir Research and Development Institute of Agriculture - Separate Branch, UFRC RAS the Republic of Bashkortostan, Kushnarenkovo District, V. Kushnarenkovo; Staff Scientist, Strategic Studies Institute of the Republic of Bashkortostan, Ufa.

E-mail:79374839931@yandex.ru

Sorokopudov Vladimir Nikolaevich - Dr. Agr. Sci., Prof., Chair of Decorative Gardening, Lawn Science, Russian State Agrarian University K.A. Timiryazev MAA, Moscow.

E-mail: sorokopud2301@mail.ru

родины черной, полученных клональным микроразмножением in vitro. Задачи исследований: проведение фенологических наблюдений, учеты зимостойкости и засухоустойчивости, общего состояния растений, учет степени поражения растений болезнями и повреждения вредителями, определение периода покоя. $B$ статье представлены результаты исследований по сортоизучению растений смородины черной (Ribes nigrum L.), полученных при помощи метода клонального микроразмножения in vitro. В качестве объектов были задействованы растения-регенеранты сортов селекции Башкирского НИИСХ - Караидель и Чишма, а также сорт Сеянец Голубки. Исследования проводились в Кушнаренковском селекционном центре 
по плодово-ягодным культурам и винограду в период с 2017 по 2019 год. Проведены фенологические наблюдения, учет зимостойкости и засухоустойчивости, общего состояния растений, степени поражения растений болезнями и повреждения вредителями, определение периода покоя. Сортоизучение растений смородины черной (R. nigrum L.), полученных методом клонального микроразмножения in vitro (сорта Караидель, Чишма и контроль Сеянец Голубки), позволило выявить вариабельность сортов по наиболее важным хозяйственнобиологическим признакам. Установлено, что данные сорта сохраняют свою стабильность в культуре без снижения качественных признаков и будут использованы для дальнейшей селекционной работы по смородине черной в условиях Башкирии.

Ключевые слова: смородина черная (Ribes nigrum L.), сортоизучение, клональное микроразмножения in vitro.

Black currant (Ribes nigrum L.) is one of the most valuable berry bushes in the Republic of Bashkortostan. Varietal composition of this crop is mainly represented by highly adaptive varieties of Bashkir selection. The varieties Karaidel and Chishma are highyielding, highly resistant, have field resistance to major diseases and pests and good shoot-forming and sprouting ability. Nowadays the varieties Karaidel and Chishma are involved in the selection of black currant as parent forms for creating new varieties. The aim of the study is to identify the variability of economic and biological characteristics of black currant varieties obtained by clonal micro-propagation in vitro. The research tasks include carrying out phenological observations, taking into account winter hardiness and drought resistance, general state of plants, taking in consideration the degree of plant damage by diseases and pests, and determining the period of rest. The study presents the results of the research on the variety study of black currant plants (Ribes nigrum L.) obtained using the method of clonal microreproduction in vitro. The objects are regenerant plants selection varieties of Bashkir RDIA - Karaidel and Chishma, as well as Seyanets Golubka variety. The research was conducted at Kushnarenkov selection center for fruit and berry crops and grapes in the period from 2017 to 2019. Phenological observations, winter hardiness and drought resistance, general condition of plants, the degree of plant damage by diseases and pests, and the determination of the dormancy period were carried out. The variety study of black currant plants (R. nigrum L.) obtained by clonal micro-propagation in vitro (varieties Karaidel, Chishma and control Seyanets Golubki) allowed to identify the variability of varieties on the most important economic and biological characteristics. It is established that these varieties have maintained their stability in culture without reducing the quality characteristics and will be used for further selection work on black currant in Bashkiria conditions.

Keywords: black currant, (Ribes nigrum L.), variety study, clonal micro-reproduction in vitro.

Введение. Смородина черная (Ribes nigrum L.) относится к числу наиболее ценных ягодных кустарников в Республике Башкортостан [1]. Сортовой ассортимент данной культуры представлен в основном высокоадаптивными сортами башкирской селекции [2]. Сорта Караидель и Чишма являются высокоурожайными, высокозимостойкими, имеют полевую устойчивость к основным болезням и вредителям, обладают хорошей побегообразовательной и побеговосстановительной способностью. На сегодняшний день сорта Караидель и Чишма задействованы в селекции смородины черной в качестве родительских форм для создания новых сортов. Главной причиной медленного внедрения в производство высокоурожайных сортов смородины черной отечественной селекции является недостаток посадочного материала. Массовое получение оздоровленного и свободного от патогенов посадочного материала возможно с помощью метода клонального микроразмножения in vitro.

Исследования по клональному микроразмножению in vitro смородины черной ( $R$. nigrum $L$.), сортов Караидель и Чишма, проводились в период с 2015 по 2019 г. в рамках научного сотрудничества в Башкирском государственном университете и в Башкирском НИИСХ. В качестве контроля при культивировании in vitro был использован сорт Сеянец Голубки. Все исследования по клональному микроразмножению in vitro проводили в соответствии с методическими указаниями [3].

Разработаны протоколы клонального микроразмножения in vitro смородины черной $(R$. nigrum L.) для сортов Караидель, Чишма и Сея- 
нец Голубки [4-6]. По результатам исследований дана характеристика морфометрических показателей посадочного материала смородины черной, полученного с помощью метода клонального микроразмножения in vitro [7].

Посадочный материал смородины черной, сортов Караидель, Чишма и Сеянец Голубки, полученный при помощи клонального микроразмножения in vitro, был высажен в 2017 году на участок сортоизучения. Следующим этапом явилось сортоизучение растений смородины черной, полученных при помощи клонального микроразмножения in vitro.

Цель работы. Выявить изменчивость хозяйственно-биологических признаков сортов смородины черной, полученных клональным микроразмножением in vitro.

Задачи исследований: проведение фенологических наблюдений, учеты зимостойкости и засухоустойчивости, общего состояния растений, учет степени поражения растений болезнями и повреждения вредителями, определение периода покоя.

Материалы и методы. В качестве объектов исследования использовали сорта смородины черной, допущенные к использованию в Госреестре селекционных достижений: Караидель (селекции Башкирского НИИСX с 2001 г. по IX региону РФ), Чишма (селекции Башкирского НИИCX с 2013 г. по IV, VII, IX регионам РФ) и в качестве контроля использован сорт Сеянец Голубки (выведен в НИИ Сибири им. М.А. Лисавенко, по I-V, VII, IX, X, XI регионам РФ) [8]. Сортоизучение растений смородины черной проводилось в соответствии с программой и методикой сортоизучения плодовых, ягодных и орехоплодных культур [9].

Результаты исследований и их обсуждение. Сортоизучение растений смородины черной, полученных при помощи клонального микроразмножения in vitro, проводилось в Кушнаренковском селекционном центре по плодовоягодным культурам и винограду в период с 2017 по 2019 год. Проведены фенологические наблюдения, учеты зимостойкости и засухоустойчивости, общего состояния растений, учет степени поражения растений болезнями и повреждения вредителями, определение периода покоя.

Фенологические наблюдения. Распускание почек смородины черной в годы наблюде- ний (2017-2019) зависело от температурного режима в весенний период. Средние даты распускания почек смородины черной по сортам: Караидель - 14 апреля, Чишма - 18 апреля, Сеянец Голубки - 13 апреля.

Цветение у сортов Чишма, Караидель и Сеянец Голубки проходило при сравнительно благоприятных условиях, заморозков в этот период не наблюдалось. Начало цветения по сортам: Караидель - 19 мая; Чишма - 16 мая; Сеянец Голубки - 9 мая. Окончание цветения: Караидель - 21 мая, Чишма - 20 мая, Сеянец Голубки - 15 мая. Период цветения составлял в среднем 3-7 дней.

При появлении первых окрашенных ягод отмечали начало созревания. У сортов башкирской селекции начало созревания ягод в среднем наблюдалось: Караидель - 10 июля, Чишма - 8 июля. У сорта Сеянец Голубки первые окрашенные ягоды появились 26 июня. Полное созревание ягод смородины черной у сортов отмечено: Караидель - 27 июля, Чишма 26 июля, Сеянец Голубки - 15 июля.

Завязываемость ягод была хорошая. Но так как возраст кустов у растений смородины черной, полученных при помощи клонального микроразмножения in vitro, составил менее 3 лет, продуктивность у сортов была незначительной. Проведена оценка по качеству ягод. Масса ягод у исследуемых сортов составила в среднем: Чишма 1,4-1,9 г, Караидель 1,2-1,7, Сеянец Голубки 1,2-1,6 г. Вкус был на уровне 4-5 баллов.

Рост побегов в первой половине вегетационного периода был оптимальным. Конец роста побегов отмечали, когда сформировались у основной части побегов верхушечные почки. Средние даты наступления окончания роста побегов у сортов: Караидель - 29 июля, Чишма - 23 июля, Сеянец Голубки - 16 июля.

Начало листопада отмечали в то время, когда осыпалось 20-25 \% листьев. Начало листопада у сортов, средние даты: Караидель 25 сентября, Чишма - 23 сентября, Сеянец Голубки - 21 сентября.

Конец листопада определяли, когда большинство растений сбросило листья. Сорта башкирской селекции Караидель и Чишма заканчивали вегетацию 20-22 октября. Сорт Сеянец Голубки - 5 октября. 
Зимостойкость и засухоустойчивость. Учет подмерзания смородины черной проводили весной при набухании почек. Зимние периоды 2017-2018 гг. характеризовались незначительным снежным покровом, в связи с этим отмечено слабое подмерзание верхней части молодых кустов, подмерзли концы однолетних побегов (балл 1 - очень слабое подмерзание). В зиму 2018-2019 гг. критических понижений температуры не наблюдалось, снежный покров установился выше кустов, подмерзаний однолетних и многолетних побегов не было.

Из всех культивируемых видов смородины наименьшей засухоустойчивостью обладает смородина черная (R. nigrum L.) [10]. Сорта смородины черной Караидель, Чишма и Сеянец Голубки рекомендованы для Уральского региона и характеризуются как засухоустойчивые. Вегетационные периоды 2017-2019 гг. характеризовались пониженными температурами и избыточным количеством влаги в летний период по сравнению с прошлогодними данными, поэтому провести сравнение между растениями смородины черной по этому показателю не удалось.

Общее состояние показывает адаптационную способность сорта и свидетельствует о степени пригодности сорта для выращивания в данной зоне. Учет общего состояния кустов смородины черной проводили дважды за вегетационный период: весной после полного распускания листьев и в конце лета - до начала листопада. Общее состояние кустов смородины черной в 2017-2018 годы в целом характеризовалось как отличное (5 баллов): здоровые кусты с сильным приростом, листья хорошо развиты. Вегетационный период в 2019 году начался рано - 8-14 апреля, в связи с повышением температуры в этот период. Затем, после распускания почек смородины черной, наступило резкое похолодание и интенсивные заморозки, что негативно отразилось на общем состоянии растений. В связи с этим общее состояние растений смородины черной в 2019 году оценивалось как хорошее (4 балла).

Учет степени поражения растений болезнями и повреждения вредителями. Во второй половине лета проводились учеты степени поражения растений смородины черной болезнями: реверсией, антракнозом и септориозом, столбчатой ржавчиной. Признаков пораже- ния не обнаружено (0 баллов). Распространение и поражение мучнистой росой сильно зависят от погодных условий, инфекционной нагрузки и сортового состава насаждений [11]. В результате наблюдений отмечено незначительное поражение американской мучнистой росой в 2019 году на всем участке сортоизучения: 1 балл очень слабое, поражены единичные листья. Единичные пораженные листья наблюдались на всех кустах, вне зависимости от их сорта. Весной, перед распусканием почек, проведена оценка у сортов смородины черной по устойчивости к почковому клещу. Признаков повреждения не выявлено (0 баллов).

Oпределение периода покоя. Изучение сроков наступления периода покоя проводили в июле, после окончания роста побегов смородины черной. Средние показатели наступления периода покоя: Караидель 25-26 августа, Чишма 13 августа, Сеянец Голубки - 19 августа. Наблюдения за выходом пазушных почек смородины черной из состояния покоя проводились с 1 ноября до 1 января. Срезанные однолетние побеги помещали в сосуды с водой при температуре 15$20{ }^{\circ} \mathrm{C}$. Начало выхода из состояния покоя смородины черной характеризовалось распусканием единичных пазушных почек на изучаемых ветках. Через 7-10 дней после распускания единичных почек наблюдалось завершение периода покоя. Средние показатели сроков завершения периода покоя у сортов: Караидель - 6 декабря, Сеянец Голубки - 30 ноября, Чишма - 9 декабря. Коротким периодом покоя, в среднем 103 дня, обладает сорт Караидель. Сорт Сеянец Голубки имеет период покоя в среднем 106 дней. Более длительный период покоя имеет сорт Чишма - 119 дней.

Выводы. Сортоизучение растений смородины черной ( $R$. nigrum L.), полученных методом клонального микроразмножения in vitro (сорта Караидель, Чишма и контроль Сеянец Голубки), позволило выявить вариабельность сортов по наиболее важным хозяйственно-биологическим признакам.

Установлено, что данные сорта сохраняют свою стабильность в культуре без снижения качественных признаков и будут использованы для дальнейшей селекционной работы по смородине черной в условиях Башкирии. 


\section{Литература}

1. Абдеева М.Г., Демина Т.Г., Шафиков Р.А. [и др.]. Плодово-ягодный сад в Уральском регионе. М., 2008. С. 78-87.

2. Нигматзянов Р.А., Головина Л.А. Новые сорта смородины черной селекции Башкирского НИИСХ // Селекция, семеноводство и технология плодово-ягодных культур и картофеля: сб. ст. науч.-практ. конф. (13-29 марта 2019). Челябинск, 2019. С. 77-80.

3. Широков А.И., Крюков Л.А. Основы биотехнологии растений. Нижний Новгород: Нижегородский госуниверситет, 2012. 49 c.

4. Ишмуратова М.М., Головина Л.А. Размножение сортов смородины черной (Ribes nigrum L.) башкирской селекции в культуре in vitro // Вестник Удмуртского университета. Биология, науки о земле, 2017. Т. 27(4). C. $455-461$.

5. Головина Л.А., Ишмуратова М.М. Укоренение в культуре in vitro сортов смородины черной (Ribes nigrum L.) башкирской селекции // Биомика. 2018. Т.10(4). С. 332-335. DOI: 10.31301/2221-6197.bmcs.2018-42.

6. Головина Л.А., Ишмуратова М.М. Оптимизация условий адаптации растенийрегенерантов смородины черной (Ribes nigrum L.) сортов башкирской селекции при переводе из in vitro в ex vitro // Известия Уфимсского научного центра РАН. 2019. № 1. C. 83-88. DOI: 10.31040/2222-83492019-0-1-83-88.

7. Головина Л.А. Морфометрические показатели посадочного материала черной смородины // Актуальные проблемы экологии природопользования в современных условиях: мат-лы междунар. науч. практ. конф. (5-7декабря 2017). Киров: Вятская ГСХА, 2017. C. 236.

8. Государственный реестр селекционных достижений, допущенных к использованию. Сорта культуры «Смородина черная» [Электронный ресурс] / ФГБУ «Госсорткомиссия», 2019. Т. 1, 2. URL: http://reestr. gossortrf.ru/reestr/culture/323.html (дата обращения: 5.02.2020).

9. Джигадло Е.Н., Долматов Е.А., Жданов В.В. [и др.]. Программа и методика сортоизучения плодовых, ягодных и орехоплодных культур. Орел: Изд-во Всерос. НИИ селекции плодовых культур, 1999. С.351-373.

10. Бурмистров А.Д. Ягодные культуры. Л.: Колос, 1972. 203 c.

11. Габышева Н.С., Сорокопудов В.Н., Протопопова A.B. Селекционная оценка генофонда смородины черной (Ribes nigrum L.) по устойчивости к болезням в условиях Якутии // Плодоводство и ягодоводство России. 2017. Т. 50. С. 97-101.

\section{Literatura}

1. Abdeeva M.G., Demina T.G., Shafikov R.A. [i dr.]. Plodovo-jagodnyj sad $\mathrm{V}$ Ural'skom regione. M., 2008. S. 78-87.

2. Nigmatzjanov R.A., Golovina L.A. Novye sorta smorodiny chernoj selekcii Bashkirskogo NIISH // Selekcija, semenovodstvo i tehnologija plodovo-jagodnyh kul'tur i kartofelja: sb. st. nauch.-prakt. konf. (13-29 marta 2019). Cheljabinsk, 2019. S. 77-80.

3. Shirokov A.I., Krjukov L.A. Osnovy biotehnologii rastenij. Nizhnij Novgorod: Nizhegorodskij gosuniversitet, 2012. $49 \mathrm{~s}$.

4. Ishmuratova M.M., Golovina L.A. Razmnozhenie sortov smorodiny chernoj (Ribes nigrum L.) bashkirskoj selekcii $\mathrm{v}$ kul'ture in vitro // Vestnik Udmurtskogo universiteta. Biologija, nauki o zemle, 2017. T. 27(4). S. 455-461.

5. Golovina L.A., Ishmuratova M.M. Ukorenenie v kul'ture in vitro sortov smorodiny chernoj (Ribes nigrum L.) bashkirskoj selekcii // Biomika. 2018. T.10(4). S. 332-335. DOI: 10.31301/2221-6197.bmcs.2018-42.

6. Golovina L.A., Ishmuratova M.M. Optimizacija uslovij adaptacii rastenij-regenerantov smorodiny chernoj (Ribes nigrum L.) sortov bashkirskoj selekcii pri perevode iz in vitro $v$ ex vitro // Izvestija Ufimskogo nauchnogo centra RAN. 2019. № 1. S. 83-88. DOI: 10.31040/2222-8349-2019-0-1-83-88.

7. Golovina L.A. Morfometricheskie pokazateli posadochnogo materiala chernoj smorodiny // Aktual'nye problemy jekologii prirodopol'zovanija v sovremennyh uslovijah: mat-ly mezhdunar. nauch. prakt. konf. (5-7dekabrja 2017). Kirov: Vjatskaja GSHA, 2017. S. 236.

8. Gosudarstvennyj reestr selekcionnyh dostizhenij, dopushhennyh $\mathrm{k}$ ispol'zovaniju. 
Sorta kul'tury «Smorodina chernaja» [Jelektronny] resurs] / FGBU "Gossortkomissija», 2019. T. 1, 2. URL: http://reestr.gossortrf.ru/

reestr/culture/323.html (data obrashhenija: 5.02.2020).

9. Dzhigadlo E.N., Dolmatov E.A., Zhdanov V.V. [i dr.]. Programma i metodika sortoizuchenija plodovyh, jagodnyh i orehoplodnyh kul'tur.
Orel: Izd-vo Vseros. NII selekcii plodovyh kul'tur, 1999. S.351-373.

10. Burmistrov A.D. Jagodnye kul'tury. L.: Kolos, 1972. $203 \mathrm{~s}$.

11. Gabysheva N.S., Sorokopudov V.N., Protopopova A.V. Selekcionnaja ocenka genofonda smorodiny chernoj (Ribes nigrum L.) po ustojchivosti $k$ boleznjam $v$ uslovijah Jakutii // Plodovodstvo i jagodovodstvo Rossii. 2017. T. 50. S. 97-101. 